\title{
Nacbleben [pervivencia] e historicidad en Walter Benjamin
}

\author{
MARIELA SILVANA VARGAS* \\ Universidad Nacional de Salta - CONICET (Argentina) \\ marielasvargas@hotmail.com
}

\begin{abstract}
Resumen
El concepto de Nachleben ocupa un lugar central en la reflexión filosófica y científica en la Alemania de finales del siglo diecinueve y comienzos del siglo veinte, tanto en su vertiente evolucionista, entendida como 'supervivencia' (Überleben), como en su dimensión histórica vinculada al estudio de la 'pervivencia' (Nachleben) de los productos culturales, y se extiende a comienzos del siglo XX a la historia del arte y a la filosofía de la cultura. Este trabajo indaga las principales características de dos formas diferentes de conceptualización de la idea de pervivencia y su vínculo con la noción de Nachleben que Walter Benjamin desarrolla en su obra. Se dará cuenta de distintos modelos o paradigmas para comprender el vínculo entre la historia, la vida y la tradición: un modelo teológico, centrado en la figura de Jesús, un modelo energético, basado en la física y otro, elaborado por Benjamin, centrado en la idea de una vida propia de las obras de arte y los objetos culturales.
\end{abstract}

Palabras Clave: Walter Benjamin, pervivencia, supervivencia, historicidad, origen, vida natural, obra de arte.

\section{Nachleben [afterlife] and bistoricity in Walter Benjamin}

\begin{abstract}
The concept of Nachleben is paramount in the philosophical and scientific reflections in late nineteenth and early twentieth Century Germany, both in its evolutionist meaning as 'survival' (Überleben) and in its historical dimension, linked to the study of the 'afterlife' (Nachleben) of cultural artifacts/products. The concept extends its application range at the beginning of the twentieth century to the Art History and the Philosophy of Culture. This paper will trace the main characteristics of two different forms of conceptualization of the idea of afterlife and its connection to the notion of Nachleben that Walter Benjamin develops in his work. In this paper I'll give an account of different paradigms or models for understanding the relation ship between history, life and tradition: a theological model, centered in the figure of Jesus, an energetic model, based on physics, and a third model, elaborated by Benjamin, centered in the idea that artworks and cultural objects have a life of their own.
\end{abstract}

Keywords: Walter Benjamin, afterlife, survival, historicity, origin, natural life, artwork.

* Dr. Phil. TU Berlín. Profesora Adjunta Universidad Nacional de Salta (Argentina). Entre sus publicaciones recientes: "La Bella Durmiente y el motivo del despertar de la juventud en el Walter Benjamin temprano" (2016); "Bello Horror. Denkbild de la revuelta" (2016), "Mexikanische Bilder in Walter Benjamins Einbahnstraße" (2017) y "Die 'Ponderación Mysteriosa': Eine Graciánsche Figur im Walter Benjamins Trauerspielbuch" (2017). 


\section{EL CONCEPTO DE NACHLEBEN EN LA HISTORIA CULTURAL ALEMANA}

Las reflexiones filosóficas en el ámbito alemán de comienzos del siglo veinte sobre la historia y la cultura se caracterizaron por estudiar las transformaciones que la modernidad trajo consigo desde una óptica que ponía de relieve la supervivencia, continuidad o pervivencia de ideas, objetos y fenómenos una vez que habían llegado a su fin. La comprensión de estos exigía la consideración no sólo de los fenómenos que los precedieron, sino de los que le sucedieron, tanto si representaban una novedad respecto a estos como si los continuaban. Este 'después', sin embargo, no se inscribe en una secuencia temporal orientada teleológicamente, en la que siempre podrían distinguirse sin mayores dificultades un antes y un después cronológicos de cada evento, sino que responde más bien a una estructura, aquella propia del despliegue de la vida póstuma, que pone en cuestión la existencia de rupturas definitivas en la historia y, con ella, la idea de un 'después' absoluto o de una emancipación sin restos del pasado, pues todo acto de pervivir o sobrevivir tiene la particularidad de estar atravesado espectralmente por reverberaciones de lo precedente. Dentro de la filosofía alemana esta forma de comprender la historia y el presente se tradujo en una figura del pensamiento, particularmente fecunda en la modernidad, expresada en el concepto de Nachleben o pervivencia, traducido al inglés como "living on, living after, surviving, afterlife, or following” (Richter, 2011: 2).

El prefijo 'nach' en alemán refiere al ámbito de la 'despueidad', de lo que viene después de algo y se halla presente en una rica variedad de sustantivos compuestos, que remiten a diferentes campos semánticos, tales como Nachfolger [sucesor], Nachfahre o Nachkomme [descendiente], Nachfrage [demanda], Nachname [apellido], Nachruf [obituario], Nachdruck [énfasis; reimpresión], Nacbtisch [postre], Nachsicbtigkeit [indulgencia] Nachtrag [suplemento], Nacbwort [epílogo], Nachhall [eco], Nachschub [adicional] y en palabras como nachber [más tarde], nachgerade [verdaderamente], nachschlagen [buscar], nachbaltig [duradero], nachträglich [retroactivo], y verbos como nachprüfen [verificar], nachahmen [imitar], nachdenken [reflexionar], nacheifern [emular], nachgeben [ceder], nachbessern [mejorar], etc. La historia de los usos adverbiales y preposicionales de la palabra 'nach' arroja cierta luz sobre esta estructura de significación que puede ser útil para la presente discusión. Como un adverbio, 'nach' significa "cerca, casi, después", mientras que como preposición posee el significado de "cerca, detrás, alrededor de, de acuerdo a".

Etimológicamente, 'nach' tenía en el alto alemán un significado espacial, denotaba contigüidad, vecindad, cercanía, como se aprecia en la palabra 'Nachbarn' [vecinos] y estaba emparentado con el término inglés 
'near' [cerca]; luego significó también "hacia" y finalmente "detrás de algo o alguien" y de "acuerdo con". El sentido temporal del término es producto de un desarrollo posterior que tradujo la cercanía o sucesión espacial en una temporal. Esta relación de co-pertenencia entre los sentidos espacial (cerca) y temporal (después) de 'nach' que devela la etimología, da cuenta de una afinidad conceptual entre ambos, pues el después en un sentido temporal, constituye también una forma de proximidad, que por su misma cercanía permanece muchas veces impensada. Vivir después de algo no significa separarse totalmente de lo que nos precedió, sino, por el contrario, estar determinado en mayor o menor medida por ello. Este fenómeno experiencial, retórico e intelectual, fue recogido en su preciso matiz semántico por el término 'Nachleben', que subyace a algunos de los desarrollos más importantes de la filosofía alemana de la cultura.

La entrada correspondiente al vocablo 'Nachleben' en el diccionario de los hermanos Jacob y Wilhelm Grimm (1889) lo define como 1) "vida posterior, vida que pervive" [nachfolgendes, nachdanerndes leben] y 2) "vida que imita" [nachahmendes leben] (90). El verbo 'nachleben' recoge también el doble significado de sobrevivir e imitar, tomar a alguien como ejemplo. En diccionarios contemporáneos se define 'Nachleben' como "la vida de un muerto en el recuerdo de sus deudos" o la "pervivencia en el recuerdo de los descendientes" (Wahrig, 2000: 901) y al verbo "nachleben" como imitar, "vivir de acuerdo al ejemplo dado por alguien". Este último significado vincula 'nachleben' con 'nacherleben', cuya definición, según el diccionario Duden Online, es "revivir a través del recuerdo algo que otros han vivido" "“Nachleben", s/f, párr. 3). Dentro de la red de sinónimos y términos asociados al concepto de Nacbleben se encuentran también términos tan diversos como los de pervivencia, sobrevida [Fortleben], [Weiterleben], supervivencia [Überleben], repetición [Wiederbolung], retorno [Wiederkehr], renacimiento [wiederaufleben], despertar [Wiedererweckung], reestablecimiento [Wiederherstellung] y renovación [Erneuerung]. El amplio e intrincado campo semántico en el que estos vocablos se encuentran insertos dentro de la lengua alemana, así como su circulación dentro de los más disímiles campos del saber, tales como la biología, la filología y la antropología explica, en parte, por qué se volvieron centrales en las reflexiones de comienzos del siglo veinte acerca de la relación entre la vida, la memoria colectiva, la herencia, la historia, la transmisión y la tradición.

Estimulada por los descubrimientos provenientes de disciplinas como la biología y la filología, dedicadas al estudio del devenir de textos y organismos vivos a lo largo de la historia, la reflexión sobre la vida se había convertido, en el umbral del siglo veinte, en un tópico presente en los más variados campos del saber. La recepción y la amplia discusión en torno a 
la teoría de la evolución de Charles Darwin que venía teniendo lugar desde finales del siglo diecinueve tuvo también una amplia repercusión en las ciencias humanas y la filosofía. La influencia de este debate en las llamadas Ciencias del Espíritu [Geisteswissenschaften] se hizo visible, por un lado, en la incorporación de la terminología propia de las ciencias naturales para pensar la historia, la cultura y la sociedad, aunque con matices propios, con los que se pretendía lograr un cierto distanciamiento de las Ciencias Naturales [Naturwissenschaften] y, por otro lado, en el creciente interés por una "filosofía de vida" [Lebensphilosophie] y una Antropología Filosófica, cuyas reflexiones giraban en torno al concepto de vida y supervivencia (Krüger, 2009; Fischer, 2009). El interés por la temática de la vida se desdobló, por un lado, en la reflexión evolucionista sobre la 'supervivencia' [survival, Überleben], y por el otro, dentro de la Historia, en el estudio de los fenómenos de 'pervivencia' [afterlife, Nachleben] ${ }^{1}$.

Entendido de esta manera, es decir, alejado del modelo evolucionista darwinista, el concepto de Nachleben se inscribía dentro de las 'Ciencias del Espíritu' en el marco de un modelo no antropomórfico de la historia de la cultura, que no se orientaba según el ritmo propio de las edades humanas (infancia, adolescencia, adultez, vejez), ni se proyectaba en estadios o etapas de desarrollo, pero que, sin embargo, consideraba que los productos culturales estaban dotados de una vida y una vitalidad propias. Pensadores tan disímiles entre sí, tales como Friedrich Nietzsche, Georg Simmel, Sigmund Freud, Wilhelm Dilthey, Aby Warburg y Walter Benjamin, colocaron en el centro de sus intereses la cuestión de la vida propia del pasado y de las manifestaciones culturales y sociales entendidas como dotadas de una energía y vida propias.

\section{Paradigmas de LA PERVIVENCIA}

El descubrimiento de la Antigüedad como objeto de estudio de las humanidades estimuló el desarrollo y el refinamiento de técnicas filológicas de decodificación de textos, que condujeron al nacimiento de la filología comparada y, en el marco de la filología griega, dieron lugar al monumental trabajo de edición de los fragmentos de los presocráticos llevada a cabo por Hermann Diels y Walther Kranz (2004). El acceso a nuevos textos del mundo grecolatino incitó a reflexionar sobre la presencia

1 La necesidad de distinguir entre el modelo darwinista de supervivencia, vinculado a las ideas de adaptación y selección natural y el modelo de las ciencias de la cultura, que no supone teleología alguna a la hora de pensar la pervivencia de ciertas formas, se muestra en el título del libro de Georges Didi-Huberman: 'L' image survivant", en el que el término que traduce "Nachleben" se utiliza como participio presente (Didi-Huberman, 2009). 
activa y eficaz de la antigüedad en la cultura alemana y de la pervivencia de los orígenes de la tradición occidental en manifestaciones culturales contemporáneas. En este sentido, al hablar de Nachleben se está haciendo referencia también a un concepto propio de la filología alemana de los años veinte. Otto Inmisch, filólogo y profesor en la Universidad de Friburgo escribe en 1919 en un folleto al que titula Das Nachleben der Antike:

Las viejas estrellas brillan nuevamente sobre nosotros. Vemos por este camino que la idea de la unicidad de los fenómenos históricos no es correcta, pues hay renovaciones y renacimientos [Wiederaufleben] que son mucho más que una mera reconstrucción histórica (Immisch, 1919: 15s).

El motivo por el que la reconstrucción y descubrimiento de las huellas de la antigüedad no posee un carácter meramente "histórico" es porque, para Inmisch, "todo lo que alguna vez vivió y obró, continúa vivo y obrando" ["Alles ïberhaupt, was lebte und wirkte, lebt und wirkt auch weiter"]. Curiosamente, el modelo para pensar la antigüedad griega y latina es el cristianismo, y más precisamente, la figura de Jesús. Immisch establece una sugerente comparación entre el estudio de la antigüedad clásica y la figura de Cristo:

Jesús puede ser entendido de manera histórica en el contexto de su tiempo; sin embargo, a él pertenecen también de modo inseparable el evangelio y la iglesia, así como su pervivencia [Nacbleben] total, permanentemente transformada y todavía transformable, hasta el día de hoy no agotada; verdaderamente no se trata de un acontecimiento "único", sino que, visto como un todo, de una enorme y continua fuente de energía (Immisch, 1919: $16 s)$.

En el enfoque filológico de Immisch se entremezclan y potencian mutuamente un paradigma teológico basado en la figura de Jesús y uno energético, que sirve de modelo para estudiar la historia de la cultura. Los productos del "espíritu" son "formas acuñadas, que viviendo se desarrollan" (Immisch, 1919: 16) y dan lugar a nuevas configuraciones, pues los contenidos y formas generan permanentemente efectos nuevos y productos intelectuales autónomos. En la expresión 'Nachleben der Antike', Immisch condensa sus posiciones en relación al pasado y a la herencia cultural. En la noción de una pervivencia de la antigüedad, conviven la idea de que la antigüedad está viva y de que es parte del actual "proceso de la vida", es decir, que no se trata de algo lejano y acabado, como lo consideraba la representación tradicional de las épocas pasadas. La 
exigencia de comprender la antigüedad se convierte en la exigencia de encarnar en el presente las formas de aquélla; no sólo de imitarlas, sino de incorporarlas a la vida.

Si la idea de un 'Nachleben der Antike' se convirtió en un paradigma para las ciencias de la cultura y la filología fue en gran parte debido a la ambigüedad del genitivo 'der', el cual puede ser entendido tanto como un genitivo objetivo como uno subjetivo. La expresión no deja en claro si se afirma que la antigüedad pervive, es decir, si continúa viviendo y manifestándose, o si nosotros la hacemos vivir, si la revivimos (nacherleben). La vida de las formas se refiere, por lo tanto, permanentemente tanto al pasado como al futuro. En los grandes pensadores de la historia cultural alemana se encuentran presentes, si bien con diferente intensidad, ambos aspectos del Nachleben, tanto el que podría denominarse "objetivo" y que refiere a los contenidos que persisten, perviven y circulan en el espacio cultural, como el que podría denominarse "subjetivo", que apela a la memoria de la posteridad e incita a las nuevas generaciones a imitar y hacer revivir el pasado (Dilthey, 2000).

El segundo paradigma de la pervivencia se moldeó sobre la base de un modelo energético, tal como el de la Escuela de Helmholtz. Autores como Freud o Warburg utilizan esta forma de explicación de un particular tipo de vínculo entre pasado y presente. Tanto Freud como Warburg consideran los afectos y el mundo psíquico en general como un sistema de energía o fuerzas, cuya característica principal es la indestructibilidad, sumada a la variabilidad. Es así como Freud entenderá el deseo y a su posibilidad de cambiar de objeto, es decir, de renunciar a un objeto investido libidinalmente y adoptar uno nuevo en su lugar. Entendidas de esta manera, las fuerzas o la energías constituyen un tipo de causa a la que se le atribuye la virtud muy particular de producir un efecto sin disminuir ella misma. En tanto una causa material puede cesar sin producir efecto alguno, una fuerza no puede volverse nula; a lo sumo puede cobrar otra forma, pues su destino es transformarse. Del mismo modo, los objetos del psicoanálisis son indestructibles y permanecen siempre vivos. El vocabulario freudiano expresa esta impronta energética en muchos de sus conceptos: abreacción, carga, descarga, quantum de afecto, libido, etc. ${ }^{2}$

Opuesto al vitalismo de la época, que postulaba la existencia de un principio vital irreductible a procesos físico-químicos de los organismos, este modelo energético pretendía integrar la fisiología a los conceptos fundamentales de la física moderna, y en especial, a la energética, a partir

2 El proyecto energético de Freud aparece formulado en el Entwurf einer Psychologie [1895]. (Freud, 1992a: 323-393). Al respecto ver también la Introducción a la epistemología Freudiana de P.-L. Assoun (1998). 
de un enfoque cuantitativo, basado en la economía nerviosa. Todo hecho psíquico era considerado, al mismo tiempo, un hecho físico y nervioso. Según Freud, las huellas o marcas en el aparato psíquico son producto de la circulación de energía psíquica. Ésta, bajo la forma de afecto, libido o pulsión, incide sobre las representaciones y las activa, es decir, las catectiza o inviste libidinalmente. La energía circula por el aparato psíquico, inervando y ligando las representaciones que constituyen la realidad psíquica, entendida como el particular sistema de huellas cargadas energéticamente. Freud consideraba que "la conservación de todos los estadios anteriores junto a la forma última sólo es posible en lo anímico" (1992b: 72). Dado el principio de constancia de la energía, los objetos investidos permanecen vivos en la psique y están dotados de eficacia. En El malestar en la cultura, Freud se vale de la evolución de Roma, la Ciudad eterna, como ejemplo de la conservación psíquica:

[...] desde que hemos superado el error de creer que el olvido, habitual en nosotros, implica una destrucción de la huella mnémica, vale decir, su aniquilamiento, nos inclinamos a suponer lo opuesto, a saber que en la vida anímica no puede sepultarse nada de lo que una vez se formó, que todo se conserva de algún modo y puede ser traído a la luz de nuevo en circunstancias apropiadas (Freud,1992b: 70).

Adoptemos, propone Freud, el supuesto fantástico de que Roma no es morada de seres humanos, sino "un ser psíquico cuyo pasado fuera igualmente extenso y rico, un ser en que no se hubiera sepultado nada de lo que una vez se produjo, en que junto a la última fase evolutiva pervivieran todas las anteriores" (1992b: 70). La metáfora de la ciudad permite reconciliar el espacio y el tiempo. La ciudad sería el espacio en tanto consiste en distintos estratos de tiempo concentrados en un solo lugar. Estas viejas estructuras, aún siendo meras ruinas, permanecen intactas y obrando en la vida y los actos de los hombres. Su retorno, acción y significado son el objeto de estudio del psicoanálisis.

Cercano a este enfoque, Aby Warburg, obsesionado con el retorno y la supervivencia de ciertos elementos de la antigüedad en la pintura del renacimiento, rastreaba la circulación encubierta de ciertos detalles del movimiento en las imágenes, que a su juicio constituían ejemplos de una singular expresión de temporalidades múltiples y diferidas y eran síntoma de una forma de vida propia de algunos objetos y fuerzas presentes en la cultura. A pesar del uso más bien discreto que se registra del concepto de Nachleben en los textos de Warburg (2010), si bien en lugares centrales, y precisamente por la ausencia de una tematización explícita de sus implicaciones epistemológicas, éste se convirtió en un reservorio de 
representaciones a partir de las cuales se pensaba la historia como aquello que sucede con la vida (Leben) de ciertos gestos, imágenes y formas expresivas durante el tiempo que siguió a un acontecimiento, entendido como su acontecer originario, expresado en el sufijo 'nach'. Para Aby Warburg el Nachleben es algo así como un remolino en la corriente del río de la historia y no algo que es meramente arrastrado por su corriente. La supervivencia de un motivo o un ornamento cobran la forma de un fantasma y síntoma - Phantom y Symptom-, son corte e irrupción de tiempos heterogéneos y lejanos en el tiempo del presente. En términos de Ernst Bloch, se trata de un momento de asimultaneidad de lo simultáneo (Ungleichreitigkeit des Gleichreitigen).

En su estudio sobre la pintura del Renacimiento, Warburg concentra su interés en los detalles del ropaje y del movimiento, pues éstos contienen y transportan aquellas energías del pasado. Se trata de una concepción energética y dinámica de la imagen y de la vida de la imagen que subraya el aspecto objetivo de la pervivencia de la antigüedad en el arte del renacimiento. En Warburg las imágenes asumen un papel fundamental en la transmisión y en la conceptualización de la supervivencia del pasado. Las Pathosformeln -fórmulas del afecto- poseen por definición una Nachleben, es decir, son capaces de pervivir y sobrevivir el paso del tiempo y son capaces de conservar y transmitir contenidos, formas y emociones, puesto que están marcadas 'engramáticamente' por las fuerzas del pasado ${ }^{4}$. Como señala Giorgio Agamben a propósito de Benjamin: "la vida de las imágenes no consiste en la simple inmovilidad ni en la sucesiva recuperación del movimiento, sino en la pausa cargada de tensiones entre ambas" (Agamben, 2010: 30). Esa tensión es lo que logra su expresión en las fórmulas del pathos warburgianas; su historia, la de los movimientos de la vida, es la historia del tiempo superviviente.

\footnotetext{
3 Didi-Huberman sostiene que el concepto de Nachleben en Warburg proviene de la antropología anglosajona, en particular, de la obra de E. B. Tylor Primitive Culture, en la que tematiza la cuestión de la tenacidad de la supervivencia [survival] en formas culturales (Didi-Huberman: 2009: 44ss.).

$4 \quad$ El concepto de 'engrama' fue tomado por Warburg de Karl Lashey, quien en sus intentos de mostrar la base biológica neuronal de la memoria, postuló la existencia de engramas o patrones de activación formados por estimulaciones internas y externas que recoge el sistema nervioso y que desembocan en el cerebro, donde producen patrones específicos de estimulación. Cada uno de estos patrones forma un engrama, cuya función es la de preservar la energía psíquica en la sustancia del cerebro.
} 


\section{NACHLEBEN EN WALTER BENJAMIN}

La idea de que un contenido, forma, idea o pathos del pasado, dotado de un valor objetivo y una vida propias, incide sobre las producciones artísticas e intelectuales del presente ocupa un lugar central en la obra de Walter Benjamin. En ésta es posible rastrear una tercera forma de reflexión, si bien no sistematizada, en torno a la pervivencia del pasado y sus manifestaciones. Si bien el concepto de Nachleben está ligado a los desarrollos benjaminianos sobre la noción de 'origen' y es inseparable del elemento mesiánico de sus reflexiones sobre la historia, los comentaristas descuidaron esta importante noción dentro de su obra. Sin embargo, este concepto es particularmente fructífero porque permite comprender mejor su concepción de la historia, así como conectar su pensamiento con el de sus contemporáneos y con la problemática de la relación entre vida, historia y memoria, omnipresente en el paisaje intelectual alemán de la primera mitad del siglo veinte.

Para Benjamin la primera tarea, previa al esfuerzo de la comprensión histórica, consiste en definir qué significa comprender históricamente. La teoría de la interpretación es definida en el Convoluto $\mathrm{N}$ del Libro de los Pasajes de la siguiente manera:

La 'comprensión' histórica se ha de tomar fundamentalmente como vida póstuma de lo comprendido [Nachleben des Verstandnen], y por eso aquello que pudo reconocerse en el análisis de la 'vida póstuma de las obras' [Nachlebens der Werke], de la 'fama', ha de considerarse como la base de la historia en general (Benjamin, 1991: V, 574-575) ${ }^{5}$.

El momento fundacional de la comprensión de una obra o un fenómeno no se asienta en un momento de presencia del sentido, de transparencia de su significado, idéntico a sí mismo y accesible a la consciencia, sino más bien sobre aquello que en la obra da cuenta del carácter radicalmente asincrónico de la comprensión. Ocuparse de lo "comprendido" no es una mera reconsideración de lo histórico, sino una forma de trato con éste que, al ceder lo presuntamente comprendido al recorrer el nudo temporal en la que la obra se enlaza todavía a lo pretérito, a la vez que revela lo que está surgiendo, es capaz de detectar aspectos novedosos e impredecibles de ella.

\footnotetext{
5 Las obras de Benjamin se citan del original alemán de acuerdo a la citación estándar de los Gesammelte Schriften: los números romanos corresponden al número de tomo y las cifras arábigas al número de página. A menos que se indique lo contrario, todas las traducciones son mías.
} 
La hermenéutica del pasado y sus productos se inicia en la comprensión de aquello que pervivió y sobrevivió en una obra y debe buscarse en su vida póstuma, como el momento en el que ésta se torna reconocible en su dimensión tanto de novedad y desafío como de repetición y restauración y, por ello mismo, de incompletud e inacabamiento. En este último elemento, en el carácter infinito e incompleto del tiempo histórico en cada uno de sus instantes y, por tanto, en tanto tiempo susceptible de ser completado, reside precisamente la dimensión mesiánica de las consideraciones de Benjamin sobre la historia. Lo inacabado del pasado, bajo la forma del sufrimiento, el olvido, la injusticia y la opresión constituye uno de los aspectos que marcan la relación entre presente y pasado. Así, en la tesis II de Sobre el concepto de historia Benjamin sostiene que:

[...] existe un secreto acuerdo entre las generaciones pasadas y la nuestra. Entonces hemos sido esperados en la tierra. Pues nos ha sido dada, tal como a cada generación que nos precedió, una débil fuerza mesiánica, sobre la cual el pasado reclama derecho. No es fácil atender a este reclamo. El materialista histórico lo sabe" (Benjamin, 1991: I, 698).

La política de Benjamin es subsidiaria de esta concepción de un pasado que no está ni muerto ni cerrado, en particular, por la idea de un pasado que puede ejercer derechos sobre el presente, y que está dotado por ello de una 'fuerza mesiánica' de lo pretérito; y que, por otro parte, amenaza con perderse y desaparecer "en cada presente que no se sienta mentado por él” (Benjamin, 1991: I, 695). Como señala Irving Wohlfarth, la tarea de una filosofía crítica de la historia consiste en liberar las energías revolucionarias que residen en lo pasado de moda, lo obsoleto y lo aparentemente olvidado (Wohlfarth, 1986: 142-168). La figura del historiador como "Chiffonier" (Benjamin, 1991: V, 482) o "Lumpensammler" (Benjamin, 1991: V, 441) -literalmente 'coleccionista de harapos'-, que recoge los desechos y los compone o monta en nuevas figuras capaces de redimir el pasado y poner en cuestión el presente, resume este enfoque.

El concepto de Nachleben atraviesa sus reflexiones sobre el destino del arte, la historia y la filosofía y tiene un rol preponderante en los análisis culturales de Benjamin y en su noción de crítica de arte. Es en este ámbito en el que el concepto alcanza su primera determinación como nexo entre las nociones de historia natural [Naturgeschichte] y vida natural [natürliches Leben] y como principio explicativo del vínculo entre las obras de arte y la vida histórica. Para Benjamin las obras de arte, los lenguajes y las ideas poseen una historicidad que no puede ser reducida al despliegue dentro de 
un continuum temporal. Su comprensión consiste, en este sentido, en dar cuenta no tanto de la obra en la historia, como de la sedimentación de la historia en la obra. Lo que está en juego en la articulación que Benjamin lleva a cabo del concepto de pervivencia es, en última instancia, la concepción de la historia, de la vida de los objetos culturales y de la función del historiador y de la crítica.

Desde cierto punto de vista, la filosofía de Benjamin es un intento por pensar y reinterpretar la historia y la tradición a partir de los conceptos de Leben [vida] y Nachleben y de Vor y Nachgeschichte [prehistoria y posthistoria]. Esta doble perspectiva, por la que el presente no existe jamás en sí mismo, separado de lo que le precedió y lo que vendrá, encuentra una de sus formulaciones más claras en el Libro de los Pasajes, donde Benjamin afirma que "es el presente el que polariza los acontecimientos en su pre- y posthistoria" (1991: V, 588). Esta característica marca todo empeño arqueológico o genealógico por explicar el surgimiento de un fenómeno: "el origen, por tanto, no se pone de relieve en el dato fáctico, sino que concierne a su prehistoria y posthistoria" (Benjamin, 1991: I, 226).

La experiencia del tiempo histórico no es nunca la de una pura presencia. Más bien, la comprensión de las "líneas directrices" de la contemplación filosófica del origen en tanto categoría histórica requieren atender a la "dialéctica inherente al origen" (Benjamin, 1991: I, 226). A este respecto el aporte central que el concepto de Nachleben permite hacer a la comprensión histórica consiste en que este es capaz de abarcar tanto el aspecto de la repetición en la historia, como el hecho de que la sucesión de épocas, formas e ideas en la historia es singular e irrepetible. Benjamin entiende la categoría de origen como una categoría histórica y no lógica, como un "remolino" en medio del río del devenir. El origen no es una descripción del proceso por el cual los objetos, las ideas, los fenómenos llegan a ser lo que son, sino lo que emerge en el proceso de su surgimiento y desaparición. El origen no es pensado ya como comienzo, sino como novedad que se conforma en torno al encuentro de un fenómeno con su pre- y su posthistoria. Este particular "ritmo" de lo originario se revela solamente a un enfoque doble que lo reconoce "como restauración, como rehabilitación, por un lado y justamente debido a ello, como algo imperfecto e inconcluso, por otro" (Benjamin, 1991: I, 226). Ese movimiento por el cual la historia se turba y llega a un origen es el movimiento de la vida no humana de las formas, las obras y las imágenes. Lo propio del torbellino del Nachleben en la historia es que rompe con el juego genealógico de las apropiaciones, de las influencias, las autorías, del antropocentrismo intrínseco a la historia de la cultura.

Es en torno a ese movimiento, que Benjamin entiende como genuinamente histórico, que puede construirse un pensamiento de la vida 
y la supervivencia de las obras de arte. Tanto las obras de arte, como las "formas puras", tienen una vida que, a raíz de su independencia e indiferencia de la vida humana, es caracterizada como un tipo de "vida natural" (Benjamin, 1991: I, 227), y que por su despliegue "claro e imperturbado" por la vida humana, su pre- y la posthistoria no constituyen "historia pura, sino que son historia natural"' (Benjamin, 1991: I, 227). Para Benjamin "la idea de la vida y de la supervivencia de las obras debe entenderse con un rigor totalmente exento de metáforas" (1991: IV, 11). Es precisamente este uso estricto y no metafórico del concepto de vida el que muestra hasta qué punto las ideas de Benjamin estaban embebidas de la terminología de la época. En Benjamin, la reflexión sobre la historia y las obras de arte como seres vivos estaba ligada además al interés epistemológico de fundar una forma de reflexión sin sujeto [ichfreie Reflexion]. La defensa de la atribución de una 'vida' a las obras literarias y a las formas artísticas supone depurar el concepto de vida de sus referencias al alma o a la sensibilidad animal. Así sostiene Benjamin que:

Ni siquiera en las épocas de mayor confusión mental se ha supuesto que sólo el organismo pudiera estar dotado de vida. Pero ello no es razón para pretender extender el imperio de la vida bajo el frágil cetro del alma, como lo intentó Fechner; ni tampoco para decir que sería posible definir la vida basándose en los actos todavía menos decisivos de la animalidad o en el sentimiento, que sólo la caracteriza ocasionalmente (Benjamin, 1991: IV, 11).

Esta concepción de la vida, no vinculada de manera esencial a formas humanas o animales de percepción o autoconciencia, se convertirá en un concepto central al interior de la reflexión alemana sobre la cultura. Dentro del plexo semántico en el que se inscribe el concepto Nachleben se encuentran también 'Überleben' y 'Fortleben', que significan "supervivencia" y "pervivencia" respectivamente, dos términos que traducen también el concepto de Nachleben y que, si bien aparecen como sinónimos, tienen un matiz semántico diferente. A diferencia de 'pervivencia', que es en cierto sentido más neutra, 'supervivencia', en tanto que es un concepto básico de la teoría evolucionista de Darwin posee una carga teórica de la que

6 "La idea de historia natural" [1932] es el texto en el que Adorno desarrolló su apropiación de este concepto benjaminiano. Acerca de su perspectiva sobre éste, Adorno sostiene que el concepto de historia natural apunta a la "la superación de la antítesis habitual entre naturaleza e historia" y aclara que su uso del concepto de naturaleza no tiene que ver con la acepción del mismo en el marco de las "ciencias matemáticas de la naturaleza", sino que guarda una íntima relación con el mito. De hecho, "mito", entendido como "lo que está ahí desde siempre, lo que sustenta a la historia humana y aparece en ella como Ser dado de antemano" sería la "traducción" que más se le aproximaría. (Adorno, 2003: 345). 
aquélla carece. Mientras que 'supervivencia' implica la superación de algún obstáculo y esfuerzos adaptativos dirigidos a ello y sólo es cabalmente comprensible en el marco del survival of the fittest y de la lucha por la existencia, 'pervivencia' expresa más bien la permanencia de algo con vida, su insistencia o persistencia, a pesar de que muchas otras cosas hayan cambiado o desaparecido. Lo que pervive tiene una sobre-vida, una vida después de la vida o una vida póstuma, posterior al ciclo vital del objeto o fenómeno, que se despliega sin luchar necesariamente contra algo que se le opone, sino por mor de una suerte de energía y temporalidad propias.

Estas consideraciones nos permiten apreciar que Benjamin desarrolla una concepción novedosa de las obras de arte, cuya consecuencia es la puesta en cuestión de la historiografía tradicional. En una carta de diciembre de 1923 dirigida a su amigo Florens Christian Rang, en la que Benjamin comenta el tema actual de sus reflexiones: el problema de "cómo las obras de arte se relacionan con la vida histórica [geschichtliches Leben]" (Benjamin, 2000: 2, 392), plantea además su tesis acerca de la inexistencia de la historia del arte como sucesión de estilos. Colocar la obra en la vida histórica, tal y como lo hacemos con los seres humanos en su relación con otras generaciones no conduce a su núcleo más íntimo, pues mientras que los seres humanos guardan relaciones de precedencia entre sí, es decir, están inmersos en la lógica de las generaciones, y su vida sería incomprensible sin referencia a categorías como muerte, decadencia o madurez, la obra de arte no resiste este tratamiento; por el contrario, ella es "de acuerdo a su esencia ahistórica" (Benjamin, 2000: 2, 392)7. El vínculo genealógico existente entre las distintas generaciones y que conecta a los seres humanos es un vínculo "extensivo", mientras que la conexión fundamental entre el paso del tiempo y la obra de arte es "intensiva". En este sentido, "la historicidad específica de las obras de arte es de tal índole [i. e. intensiva] y no se revela en la historia del arte, sino sólo en la interpretación" (Benjamin, 2000: 2, 392). En la interpretación, la crítica y la traducción la vida de la obra de arte entrega su carozo propiamente histórico bajo el manto de la eternidad: "en la interpretación las relaciones entre las obras de arte se presentan como eternas aunque no sin relevancia histórica" (Benjamin, 2000: 2, 393).

Benjamin expresa así su rechazo a una metodología de la historia del arte que concibe a ésta como una descripción genealógica de la sucesión de las obras de arte a lo largo de la historia, que señala los nacimientos, la decadencia y muerte de los estilos y se ocupa de establecer relaciones de influencia, parentesco, etc. El proyecto del Libro de los Pasajes partía así de

Las cartas de Benjamin se citan de acuerdo al modo de citación estándar: primero se indica el número de tomo y luego el número de página. 
la idea de que "no hay épocas de decadencia" y se proponía "intentar ver el siglo XIX de un modo tan absolutamente positivo como me esforcé en ver el siglo XVII en el trabajo sobre el drama barroco" (Benjamin, 1991: $\mathrm{V}, 571)$. Mientras que la narración que propone la historia del arte tradicional no conduce al núcleo de la obra de arte, pues sólo "se reduce a una mera historia de sus materiales o de la forma, para las cuales las obras de arte sólo consisten en ejemplos o, en cierto modo, modelos", Benjamin considera necesario plantearse "la cuestión de una historia de las obras de arte como tal" (Benjamin, 2000: 2, 392), es decir, dar cuenta del aspecto procesual de la obra.

Como se ve, este alejamiento de Benjamin, similar al que lleva a cabo Warburg, de una interpretación de los productos culturales desde un esquema biologicista, que entiende el despliegue de los mismos en la historia a partir de conceptos como vida, muerte, grandeza y decadencia de las épocas históricas y de los productos culturales, no es equivalente al rechazo de la idea de que éstos poseen una vida:

La indestructibilidad de la vida más alta en todas las cosas. Contra los agoreros de la decadencia. [...] Nunca importan los 'grandes' contrastes, sino sólo los contrastes dialécticos, cuyos matices, a menudo para confusión, aparecen semejantes. Pero de ellos se engendra la vida siempre diferente (Benjamin, 1991: V, 573).

Con la impugnación del modelo antropocéntrico de comprensión de las obras, Benjamin avanza en una propuesta historiográfica que considera capaz de hacerles justicia. Así, la tarea propia de la crítica filosófica y la historia del arte consiste en analizar y exponer la singular relación entre historia, obra y vida propia de los productos culturales.

\section{CONCLUSIÓN: UNA HISTORIA ESPECTRAL}

El esfuerzo de Benjamin por elaborar una teoría de la interpretación de las obras de arte puede resumirse en dos ideas que articularán su tarea como crítico cultural e historiador de la modernidad: la postulación de una relación particular entre las obras y la historia; y la tesis de que las obras de arte tienen una vida (in)diferente a la vida humana. Esta concepción de las obras de arte como formas de vida y como objetos capaces de transmitir contenidos cargados, a su vez, de vitalidad es un elemento que modifica la relación de éstas con la historia. Estos planteos conducen a una revisión de la categoría de historicidad y de los fundamentos mismos de la historia e inaugura una consideración de la historia a partir de su carácter espectral. La historia es eso que tiene lugar, también como 
disciplina, entre lo muerto y renaciente a la vez (Didi-Huberman, 2009). En esta perspectiva los "muertos" (corrientes, estilos, ideas, tendencias, prácticas, símbolos, significados) no mueren del todo, sino que sólo asumen otras formas de vida, parasitan, enriquecen y contaminan las formas de expresión de las nuevas generaciones. Cada vez que un objeto es dado por muerto, se empieza a entrever y reconocer su renacimiento. El carácter espectral de esta historia consiste en que aquello que pervive o que vuelve desde épocas remotas no está bajo control de los sujetos que lo experimentan o reconocen, así como tampoco la acción originaria está gobernada por un sujeto, sino que es el resultado del encuentro e interacción entre el nacer y el devenir.

La vida que circula en las obras y la historia, los contenidos que habitan las imágenes no se hallan en posesión de 'sujetos' capaces de dar razón de ellos. Por este motivo, su cognoscibilidad está marcada por un cierto diferimiento temporal. Se los descubre siempre después, de manera retroactiva, a través de la discontinuidad y la intermitencia propia de la vida de las obras. Ellas albergan una experiencia no humana de la vida, pero vinculada a ella. Precisamente gracias a aquello que la vida humana tiene en común con la vida histórica es posible el encuentro con el pasado. En este sentido, Nacbleben describe y revela estados producto de la reaparición no buscada de ciertos fenómenos y procesos de eficacia inconsciente, de transmisión sin emisor ni receptor, de pervivencia de aquello que se ha dado por perimido, o que, negado, reaparece con un poder inquietante. En la pervivencia no importa ya lo que efectivamente fue, sino la forma que los fenómenos cobran en el presente. El Nachleben no constituye una variante del 'eterno retorno' de Friedrich Nietzsche, ni tampoco forma parte de la 'morfología de la historia universal' de Oswald Spengler, pero descubre, por un lado, una relación entre presente y pasado que no es la de la mera sucesión temporal, la influencia, la causalidad y que tampoco responde al recuerdo o la evocación conscientes, y por otro, muestra esta relación como producida por la cultura, en tanto la muerte y la vida que están inscritas en ella dependen del espacio de la tradición y de formas particulares de transmisión. En esta posibilidad de una comprensión novedosa de la historicidad y la tradición reside hoy la actualidad de Walter Benjamin.

\section{REFERENCIAS}

-Adorno, Th. (2003). Die Idee der Naturgeschichte. En Th. Adorno, Gesammelte

Schriften (Tomo I). Philosophische Frühschriften. Fráncfort del Meno: Suhrkamp.

-Agamben, G. (2010). Ninfas. Valencia: Pre-Textos. 
-Assoun, P.-L. (1998). Introducción a la epistemología Freudiana. México: Siglo XXI. -Benjamin, W. (1991). Gesammelte Schriften. Fráncfort del Meno: Suhrkamp.

-Benjamin, W. (2000). Gesammelte Briefe. Fráncfort del Meno: Suhrkamp.

-Didi-Huberman, G. (2009). La imagen superviviente. Historia del arte y tiempo de los fantasmas según Aby Warburg. Madrid: Abada.

-Diels, H.; Kranz, W. (Eds.). (2004). Die Fragmente der Vorsokeratiker. Hildesheim: Weidmann.

-Dilthey, W. (2000). Dos escritos sobre hermenéutica. Madrid: Istmo.

-Fischer, J. (2009). Philosophische Anthropologie. Eine Denkrichtung des 20. Jahrhunderts. Munich: Karl Alber.

-Freud, S. (1992a). "Proyecto de Psicología". En S. Freud, Obras Completas. Vol. 1. Bs. As.: Amorrortu.

-Freud, S. (1992b). El malestar en la cultura. En S. Freud, Obras Completas. Vol. 21. Bs. As.: Amorrortu.

-Grimm, J.; Grimm, W. (1889) Deutsches Wörterbuch. Tomo 7. Leipzig: Hirzel.

-Immisch, O. (1919). Das Nachleben der Antike. Leipzig: Dieterich.

-Krüger, H-P. (2009). Philosophische Anthropologie als Lebenspolitik. Deutsche Zeitschrift für Philosophie. Sonderband 23. Berlín: Akademie Verlag.

-Nachleben. (s/f). En Duden Wörterbuch Online. Recuperado de http://www.duden.de/rechtschreibung/nachleben

-Richter, G. (2011). Afterness. Figures of following in modern thought and aesthetics. New York: Columbia University Press.

-Treml, M. (2007). Warburgs Nachleben. Ein Gelehrte und (s)eine Denkfigur. En D. Weidner \& M. Treml (Eds.), Nachleben der Religionen. Kulturwissenschaftliche Untersuchungen zur Dialektik der Säkularisierung (pp. 25-40). Munich: Fink.

-Wahrig Deutsches Wörterbuch (2000). Munich: Bertelsmann Verlag.

-Warburg A. (2010). Werke. Berlin: Suhrkamp.

-Wohlfarth, I., (1986). Et Cetera? The Historian as Chiffonnier. New German Critique, 39, 142-168.

Sumario: 1. El concepto de Nachleben en la historia cultural alemana; 2. Paradigmas de la pervivencia; 3. Nachleben en Walter Benjamin; 4. Conclusión: una historia espectral; Referencias. 